\title{
Dorsal and palmar aspect dimensions of hand anthropometry for designing hand tools and protections
}

\author{
M. Vergara, M. J. Agost, V. Gracia-Ibáñez
}

Abstract.

\begin{abstract}
Most hand anthropometric studies are performed on the palmar aspect, while dimensions of the dorsal aspect are also useful in ergonomics and hand modelling. A survey of hand anthropometrics for a Spanish population (69 females, 70 males) is presented. Landmarks were selected to compare lengths from the dorsal and palmar aspects and to be useful for hand modelling and ergonomics design. Ninety-nine dimensions of fingers and thumb of the right hand (41 lengths, 32 depths, 26 breadths) were collected, including thumb breadths and depths. Descriptive statistics of all the dimensions are presented. Lengths were measured from both dorsal and palmar aspects and paired lengths compared through T-tests. Significant differences were found in almost all the lengths, showing that databases should explicitly state the aspect (dorsal or palmar) where dimensions have been measured. The data provided are useful for designing tools and hand protections and developing hand models more accurately.
\end{abstract}

Keywords: Hand anthropometry, palmar aspect, dorsal aspect, hand tools.

\section{Introduction}

Hand anthropometry is a relevant topic that has been studied from different approaches. From an ergonomic perspective, hand dimensions of specific populations are characterized in order to optimize manual tools, equipment, gloves or other hand spaces or device dimensions (Cakit, Durgun, Cetik, \& Yoldas, 2014; García-Cáceres, Felknor, Córdoba, Caballero, \& Barrero, 2012; Imrhan, Sarder, \& Mandahawi, 2009; Kwon, Jung, You, \& Kim, 2009; Mandahawi, Imrhan, Al-Shobaki, \& Sarder, 2008; 
Obi, 2016; Okunribido, 2000). Results from these analyses are especially relevant for tool designers and manufacturers, as they can use them to create devices fitted to workers and users of different populations and percentiles, thereby improving work efficiency, comfort and safety. Anthropometric data is also required for developing 3D hand models (Harih \& Dolšak, 2013, 2014; Rogers, Barr, Kasemsontitum, \& Rempel, 2008), and for studying the kinematics of the human hand and developing biomechanical hand models with a wide range of applications which range from workspace design to clinical analysis (Armstrong et al., 2009; Buchholz, Armstrong, \& Goldstein, 1992; Sancho-Bru et al., 2011). Other notable applications of hand anthropometry are the estimation of palm and hand surface areas in toxicology research, thermal physiology and skin burn studies (Choi et al., 2011; Hsu \& Yu, 2010; Yu, Yick, $\mathrm{Ng}, \&$ Yip, 2013) and the determination of personal parameters (such as sex, age or stature) in accidents or mass disasters in the forensic field from their correlation with hand dimensions (Agnihotri, Agnihotri, Jeebun, \& Googoolye, 2008; Ishak, Hemy, \& Franklin, 2012a, 2012b; Kanchan \& Krishan, 2011; Krishan \& Sharma, 2007; Sen, Kanchan, Ghosh, Mondal, \& Krishan, 2014).

The needs of these applications in order to get accuracy are very different. Some of them may require just dimensions from the skin (toxicology) while others require knowledge of the internal parts such as bones and joints (biomechanical models). In general, the data reported in the literature has been collected externally, using different landmarks on the skin which, when needed, are referred to the appropriate internal element.

When collecting anthropometric dimensions externally, choosing landmarks plays an important role in accuracy: they should be reproducible, be minimally affected by skin stiffness and tissue deformation and, when needed, correspond to internal 
references or elements. In the case of the hand, the chosen landmarks may be quite different when considering dorsal or palmar aspect. Creases in the palmar aspect can be easily identifiable, but in some cases do not refer exactly to any internal structure (e.g. creases of palm) or are difficult to select because of the presence of various creases in the same landmark. On the contrary, some landmarks on the dorsal aspect can be more affected by skin movement. In any case, for each application, the appropriate dimensions should be considered from the dorsal, palmar or both aspects of the hand. Studies in the literature usually report the aspect considered by using illustrations (Cakit et al., 2014; García-Cáceres et al., 2012; Imrhan et al., 2009; Li, Chang, Dempsey, Ouyang, \& Duan, 2008) or by reporting the hand posture while measuring (Mandahawi et al., 2008). The palmar aspect is frequently used to define hand lengths, both in forensic (Agnihotri et al., 2008; Sen et al., 2014) and ergonomic studies (Cakit et al., 2014; García-Cáceres et al., 2012; Imrhan et al., 2009). The standard ISO 7250-1: 2008 (2008) also defines hand dimensions with illustrations of the palmar aspect. Even when comparing or validating methods of collecting hand measurements (Li et al., 2008; Yu et al., 2013), lengths are measured on the palmar side. In all, there is little concern about lengths in the dorsal aspect on the hand. However, these dorsal lengths are needed in applications such as designing protections and gloves. When trying to fit the protection to the hands, both aspect should be considered: in the case of the palmar side in order to have better control of the objects or tools grasped and in the case of dorsal hand in order to the protection allow to bend the digits naturally, without interference. Yu et al. (2013) used some dorsal points when extracting lengths from 3D scanning; however, the points used had been positioned according to landmarks on the palmar aspect because they considered that the landmarks on the dorsal aspect for lengths are not easily identifiable. Furthermore, they define hand length measurements 
in both palmar and dorsal aspects, although the landmarks were chosen to be equivalent from both hand aspects.

The dorsal aspect is usually considered to locate landmarks for defining breaths, depths or circumferences. Nevertheless, the landmarks used in breadth measurements are usually the maximum external points (Cakit et al., 2014; Imrhan et al., 2009), so again they are the same regardless of the aspect used.

In spite of the fact that only the palmar aspect is considered in most of the studies, these anthropometric data of the hand are afterwards used as a reference for designing hand protections and developing hand models, which may lead to inaccuracies that has not been analysed yet. For example, when phalanges are flexed their lengths become longer in the dorsal aspect and shorter in the palmar one (Burm, Chung, \& Oh, 1999). These differences in dimensions in the palmar and dorsal aspects can have some implications, for example, in the design of better-fitted gloves when trying to include a different rigidity in the joints regions.

The aim of this work is to present hand anthropometric dimensions useful for the design of hand tools and protections and developing hand models and analyse the differences between the aspect (dorsal or palmar) in which dimensions have been measured.

Ninety-nine anthropometric dimensions of the right hand of a Spanish population useful for designing hand protections have been collected and reported: 41 lengths, 32 depths and 26 breadths. Considering accessibility to equipment and in order to reduce collecting time and errors, 2D photo processing was also used instead of only manual methods, which are more time consuming and no significant differences for hand dimension have been found (Habibi, Soury, \& Zadeh, 2013). Most of the 
dimensions were taken from photographs; only some depths were measured manually (including palm, wrist and some fingers) because the photographs were difficult to be taken without loss of accuracy. Lengths have been measured both from landmarks placed on the dorsal and palmar aspects of the hand and have been compared to check significant differences.

\section{Methods}

\subsection{Participants}

One hundred and thirty-nine healthy adults (69 females and 70 males) with no deformity or disability in their hands participated voluntarily in this study, without any economic reward. The experiment was approved by the Ethical Committee of the University and the participants gave their written consent. All the participants come from four provinces in the Mediterranean region, in northeastern Spain. Measurements were taken over a period of three months. Some basic descriptive statistics of the sample are shown in Table 1.

Insert Table 1 near here

Table 1. Descriptive statistics of the sample.

\subsection{Measurement instruments and procedure}

Photographs and manual methods were combined in the collection of data in order to minimize measurement time while maintaining the accuracy of the measurement procedure. In order to adjust the camera parameters and the post-processing method (scaling photographs and measuring), a pilot study with 4 subjects was performed previously (not reported here for brevity), where several hand measurements were taken 
manually with callipers and also from photographs of the hand placed on a calibrated grid paper. The results showed that by using the highest camera zoom (Fujifilm T500, zoom $288 \mathrm{~mm}$ ) and adjusting the distance of the camera to frame exactly the hand, the distortion due to the perspective was minimal (i.e. reducing the error due to the visual line of the camera of hand landmarks with respect to the grid) when processing the data. First, some landmarks were drawn on the skin of the hand. Limits of the phalanges for fingers and thumb were marked from a dorsal view with flexed digits (Fig. 1a to 1e) in the midpoint of the curve (where the extensions of the two parts of the joint would intersect). The limit of the hand with the wrist was palpated on both the dorsal and the palmar aspects. For the dorsal aspect, the limit was identified with the wrist extended (around $40^{\circ}-50^{\circ}$, Fig. 1f), while for the palmar aspect the limit was identified with the wrist flexed (around $50^{\circ}-60^{\circ}$ Fig. 1g). Finally, metacarpal directions and limits of each finger and thumb were marked by palpating the bones (Fig. 1h) near these marks. Creases of the joints of the fingers in the palmar view were used as landmarks (although they were not marked).

\section{Insert Figure 1 near here}

Figure 1. Marking limits of phalanges and metacarpals: from a) to e) limits of phalanges; $f$ ) and $g$ ) limits of hand (metacarpals with the wrist); h) limit of each metacarpal (direction).

Once the hand had been marked for each subject, 5 photographs were taken while placing the hand on a sheet of gridded paper placed next to the corner of a wall. An example of the photographs taken for one subject is shown in Figure 2. Note that photographs of the whole hand from both aspects were taken.

The subjects were standing and placed the hand (or finger) on the gridded paper, while adopting a comfortable posture with the body and arms. Figure 3 shows an 
example of the body and arms postures adopted while taking the photographs. The photographs were taken by adjusting the distance of the camera to frame exactly the hand.

In manual measurements, a spreading calliper (GPM anthropological instruments, DKSH) with rounded ends and measuring range of 0-300 $\mathrm{mm}$ was used (Fig. 4).

Insert Figure 2 near here

Figure 2. Example of the 5 photographs of the hand and fingers with landmarks for one subject. A: dorsal view of the whole hand, B: palmar view of the whole hand, C: lateral view of thumb, D: dorsal view of thumb, E: lateral view of index.

Insert Figure 3 near here

Figure 3. Example of the body and arm postures. From left to right: dorsal and palmar view of the whole hand, lateral and dorsal view of thumb, and lateral view of index.

Insert Figure 4 near here

Figure 4. Examples of some hand depths measured with a spreading calliper.

Finally, the photographs were post-processed in AutoCAD® to adjust the scale using the grid and then to measure the dimensions. All hand lengths and breadths were measured from the photographs, as well as thumb and index finger depths. Manual measurements were used for the rest of the depths, since taking photographs was more complicated or even impossible.

In order to compute the repeatability and reproducibility errors of the whole process of drawing landmarks and measuring, both from photographs and manually, a study was developed with two operators and two subjects. Each operator performed the whole 
process of marking and measuring all the dimensions to each subject in two different days. Repeatability and reproducibility errors were estimated as the mean residual standard deviation (MRSD) from different ANOVAs, with different factors (Altman \& Bland, 1983):

- Repeatability error of all the dimensions globally: factors dimension and subject. This variability is associated with the 4 measurements performed in each subject for all the dimensions, i.e. is due to the repetition of the whole process of palpation and measuring of all the dimensions.

- Reproducibility error of all the dimensions globally: factors dimension, operator and subject. This variability is due to the whole process of palpation and measuring and also to the errors introduced by the operator.

- Repeatability errors of each dimension separately: 99 ANOVAs with factor subject, one per each dimension. This variability is due to the process of palpation and measuring of each the dimension individually. These errors were computed in order to consider the relative error of each dimension (ratio error/dimension).

Two graduate students were appropriately trained by the first author to perform the measurements.

\subsection{Hand anthropometric dimensions}

The selection of hand anthropometric dimensions was based on three main criteria. First, we were interested in hand measures that are useful for ergonomics (surface and joints) and hand modelling. Second, some dimensions that are usually reported in other studies have been included in order to compare the results with other populations. 
Finally yet importantly, our approach required the study of some hand dimensions from both aspects in order to compare them, at least for lengths.

Table 2 lists the 99 anthropometric dimensions finally selected (41 lengths, 32 depths and 26 breadths) and measured on the right hand of the participants, using the methods explained in the previous section.

The coding used to name the hand dimensions is composed of two or three codes. The first code refers to the nature of the dimension (L: Length; B: Breadth; D: Depth). The second code refers to the part of the hand where the dimensions were taken. For fingers, the second code is composed of various other codes: a number identifying the finger (1: Thumb; 2: Index finger; 3: Middle finger; 4: Ring finger; 5: Little finger) and some letters identifying the region, i.e. phalanges (DP: Distal Phalange; MP Medial Phalange; PP Proximal Phalange) or metacarpal region (MC: Metacarpal); joints (DIP: Distal Interphalangeal joint; PIP Proximal Interphalangeal joint, IP: Interphalangeal joint, only for thumb; MCP: Metacarpophalangeal joint); or other regions (B: Base of the finger; $\mathrm{S}$ : Skin; C: Centre). For dimensions that are not specific to the fingers, the second code is: H: Whole Hand; P: Palm; W: Wrist. Finally, some dimensions have a third code identifying the aspect in which the lengths were measured (dv: Dorsal view; pv: Palmar view). Therefore, as an example, the hand dimension "L1DP_dv" corresponds to: (length) (thumb) (distal phalange)_ (dorsal view). Likewise, "B1DP” means (breadth) (thumb) (distal phalange). For a more comprehensive description of the dimensions, see Figures 5 and 6.

Insert Table 2 near here

Table 2. Hand dimensions considered in the study. * Thumb Skin: Junction between palm and thumb at the Carpometacarpal joint of the thumb. 
Figure 5 shows all the hand measurements that were taken from photographs. Figure 6 shows the points where depths were measured manually. Note that all the depths were measured perpendicularly to the image (i.e. from the point marked in the palmar aspect to the same point in the dorsal aspect) except for the depths related to the thumb (DPB1, D1MCP), which were measured across the thumb (see Figure 4).

\section{Insert Figure 5 near here}

Figure 5. Hand measurements taken from photographs: all lengths and breadths, and some depths.

\section{Insert Figure 6 near here}

Figure 6. Points where the hand depths were measured manually. Note that depths related to the thumb (DPB1, D1MCP) were measured across the thumb (see Figure 4), not perpendicular to this image.

\subsection{Data analysis}

The data collected were analysed with the SPSS statistical software (IBM SPSS 22 for Windows). Descriptive statistics (mean, standard deviation -SD- and percentile values) were obtained for each anthropometric dimension for females and males separately, and for all participants jointly. Normality of distribution was tested for each dimension, using the Kolmogorov-Smirnov test, at the 5\% level of significance, also separately by gender and jointly.

Dimensions (lengths) measured from both the dorsal and the palmar aspects were compared using paired-sample T-tests, at the 5\% level of significance. 


\section{Results}

The repeatability and reproducibility errors (RMSE) of the first two ANOVAs have the same magnitude: $1.8 \mathrm{~mm}$, and the factor operator is not significant in the ANOVA, which means that the operator does not introduce any additional error. Table 3 shows the mean values of the repeatability errors results from the 99 ANOVAs. It shows the absolute errors in mm (RMSE) and the relative errors in percentage of the affected dimension (ratio RMSE/dimension). The data is reported aggregated with different criteria: globally, and distinguishing by method of measurement (manual/photographs), by type of dimension (lengths/breadths/depths) and, for the lengths, by the aspect (dorsal/palmar). Note that the relative errors are similar for dorsal and palmar lengths (3.3\%), and a bit higher for the dimensions measured manually (4.1\%) than for the measured from photographs .

\section{Insert Table 3 near here}

Table 3. Repeatability errors of the dimensions separately. Mean values of the 99 ANOVAs in mm (RMSE) and in ratio (RMSE/dimension). Values reported globally, and per method or per dimension.

Tables 4 to 7 shows typical descriptive statistics (mean, standard deviation, and 5th and 95th percentiles of the sample) of hand anthropometric dimensions for females $(n=69)$, males $(n=70)$ and all participants jointly. Some exceptions in the total number of measurements should be considered for some dimensions. For L1S, some data have been discarded, since the hand was in an imprecise posture (for females $n=55$, for males $\mathrm{n}=61$ ). Four manually measured dimensions (D2MCP, D4MCP, D5MCP, DPB5) were 
not considered from the beginning of the study, but they were incorporated when data gathering had already begun. The sample is smaller in these cases: $\mathrm{N}=20$ for females and $\mathrm{N}=40$ for males.

The normality test showed that only 9 of the 99 dimensions (6 lengths and 3 depths) were distributed normally considering all participants jointly $(\mathrm{p}<0.05)$. For females, 16 dimensions were distributed normally (all them were lengths) and for males, 24 dimensions showed a normal distribution (19 lengths, 3 breaths and 2 depths). These normally distributed variables are shown in Tables 4 to 7 with an asterisk next to the mean.

Insert Table 4 near here

Table 4. Descriptive Statistics for right-hand dorsal lengths $(\mathrm{mm})$ of the sample. * Normally distributed dimension. $S D=$ standard deviation; 5th, 95 th $=5$ and 95 percentile values. Abbreviations of dimensions are shown in Table 2 and figures 5 and 6.

Insert Table 5 near here

Table 5. Descriptive Statistics for right-hand palmar lengths ( $\mathrm{mm}$ ) of the sample. * Normally distributed dimension. SD= standard deviation; 5th, 95th= 5 and 95 percentile values. Abbreviations of dimensions are shown in Table 2 and figures 5 and 6.

Insert Table 6 near here

Table 6. Descriptive Statistics for right-hand breadths $(\mathrm{mm})$ of the sample. * Normally distributed dimension. $S D=$ standard deviation; 5 th, 95 th $=5$ and 95 percentile values. Abbreviations of dimensions are shown in Table 2 and figures 5 and 6.

Insert Table 7 near here

Table 7. Descriptive Statistics for right-hand depths ( $\mathrm{mm}$ ) of the sample. * Normally distributed dimension. $S D=$ standard deviation; 5 th, 95 th $=5$ and 95 percentile values. Abbreviations of dimensions are shown in Table 2 and figures 5 and 6. 
Table 8 shows the results of the paired-sample T-tests: mean differences (dorsal view palmar view, across subjects), standard deviation, t-values (with $*$ denoting bilateral critical value of the t-tests) and ratios (in percentage) of the mean differences with respect to dorsal view dimensions (mean differences/mean dorsal view dimension). Note that the ratios of the mean differences observed are higher than the repeatability errors obtained in the previous study. The paired-sample T-tests showed that, in general, means of dimensions measured by both aspects of the hand were significantly different. Significant differences appear in all cases except for L1DP, L3DP, L4DP and L5DP (for females), L1PP, L3DP and L4DP (for males), or L1DP, L3DP and L4DP (jointly). Difference of means varies in a range from -33.6 to $20.9 \mathrm{~mm}$ for females, from -36.0 to $23.2 \mathrm{~mm}$ for males and from -34.8 to $22.1 \mathrm{~mm}$ jointly. Biggest differences appear for the dimensions that involve the metacarpophalangeal joint of the fingers, leading to shorter dimensions of the metacarpus (negative differences in L2MC, L3MC, L4MC, L5MC) and longer dimensions of the proximal phalanges (positive differences in L2PP, L3PP, L4PP, L5PP), both in the dorsal aspect.

\section{Insert Table 8 near here}

Table 8. Results of the paired t-tests comparing hand lengths measured on the dorsal and the palmar view. Differences are considered as dimension in dorsal view - same dimension in palmar view), SD: standard deviation of differences, $t: t$-values of each test, *: bilateral critical value <0.01, \%Diff: ratio between the mean differences with respect to dorsal view dimension (mean differences / mean dorsal view dimension) in percentage.

\section{Discussion}

Descriptive statistics (M, SD and selected percentiles) of 99 right-hand anthropometric dimensions have been presented for a new population (Mediterranean, northeastern area of Spain) enriching hand anthropometric data publications. Previous 
hand anthropometric studies (Lee and Jung, 2015) have failed to consider the breadth and circumference of the thumb. In this study, breadth and depth of the thumb are reported, so that this gap can be partially filled. All the data presented is expected to serve as a useful reference for designing hand protections and developing more accurate hand models, as well as for other purposes such as developing hand surface area estimations.

Although the landmarks used in the dorsal aspect are relatively new, they have been proved to be as reproducible as the palmar aspect ones, so that they can be used as reliable references.

Although length measurements are usually taken in the palmar aspect, this study reports new data referring not only to the palmar aspect but also to the dorsal aspect and sheds new light on the fact that there are significant differences (through paired-sample $\mathrm{T}$ tests) between most of the hand lengths depending on the (dorsal or palmar) aspect. These significant differences are predictable in some cases, when measurement limits are clearly different according to the hand aspect (as is the case of proximal phalanges or metacarpal lengths) due to the different landmark for the MCP joint. In other cases, however, these differences are not so obvious, as for medial or distal phalanges or the whole hand length. Cases with no significant differences between both aspects (at a $1 \%$ level) only occur for lengths at the distal joint for some fingers.

One direct application of these results is linked to the design of gloves. Gloves are generally used to protect workers' hands from mechanical hazards, chemical agents, extreme temperatures, etc. However, the use of gloves may have negative effects on manual dexterity, tactile sensitivity or comfort, among others (Dianat, Haslegrave, \& Stedmon, 2012). One of the main aspects of dexterity that seems to be affected by gloves is the restriction of movement/bending of fingers (Dianat, Haslegrave, \& 
Stedmon, 2012). This negative effect on dexterity caused by gloves could be reduced using the results of this work. If the glove adjust perfectly to the tip of a digit, the distance from the tip of the glove to the regions where the protective material should be more flexible to allow for a more natural movement of the fingers may consider these results. For example, focusing on the proximal interphalangeal joint, significant differences have been observed for the length of all the medial phalanges between dorsal and palmar aspects, while for the distal phalanges the differences are small or not significant. This means that the more flexible region in the distal joint should be at the same distance from the tip, while for the proximal joint it should be placed closer to the tip in the palmar aspect than in the dorsal one.

Different behaviours have been observed depending on the specific finger. For index finger, significant differences between means are detected in all cases (for females, males and jointly), while conversely for ring finger no significant difference is detected for any sample. It therefore seems that the configuration of the distal joint depends on the finger considered, at least for the population under study. The rest of the lengths compared also present significant differences. These results should be considered when consulting hand anthropometry databases in order to ensure that the measurements are taken in the desired hand aspect.

When the fingers are bent, their lengths are different in the two aspects, becoming longer in the dorsal aspect and shorter in the palmar one (Burm et al., 1999). In this work, the dimensions were measured with the hand on a plane, so that they are not completely functional for design, considering that the posture is static and non-grasping. However, the way the landmarks were selected is more appropriate and complete for design than those previously reported by other authors (with data only from the palmar 
aspect with the flat hand). In particular, for the case of phalanges, dorsal landmarks have been placed with the digits flexed, and palmar landmarks are the creases of phalanges, so that in both cases these dimensions represent better the size of the phalanges when digits flex. Although the dimensions presented have been taken with the flat hand in a static posture, they are expected to be more reliable to design protections and other devices that fit better to phalanges when digits flex in both aspects of the hand. Further work should consider changes in the dimensions in functional tasks, with other postures of the hand to improve their applicability in both design and modelling.

Compared with the results presented by other studies, more concerned with normative dimensions, the landmarks used here were selected with a more functional point of view. This fact causes some remarkable differences in comparing these data with those previously reported. As an example, the landmark to define total hand length was considered with the wrist flexed or extended, depending on the aspect. However, the normative data consider the hand length landmark as the styloid processes, thereby explaining evident differences.

On reviewing some of the hand dimensions presented in other databases that are equivalent to the data presented here, it can be observed that in this study both males and females have thinner hands (BP) than the Spanish working population considered in Carmona Benjumea (2003); females also have thinner hands than Colombian working females (García-Cáceres et al., 2012). In contrast, in this study the population has wider hands than Turkish dentistry students (Cakit et al., 2014). These differences may be due to the different ages and/or origin considered, and to the effect of being only a working or student population, while in this study the range of occupations is more varied. As some differences with other populations have been found, the results about differences 
between dorsal and palmar aspect dimensions should be limited to similar populations. Future studies should consider the effect of other factors such as race and region on the results. With regard to hand lengths, the dorsal values reported here are more similar to other databases in the literature than the palmar ones, due to the landmark positioning, discussed above.

\section{Conclusions}

Ninety-nine hand anthropometric dimensions of a population from the Mediterranean region (northeastern area of Spain), not reported previously, are presented. Thumb breadths and depths are also reported, which are not usually found in hand anthropometric studies.

Twenty hand lengths were measured from landmarks selected from both the dorsal and the palmar aspects with the aim of being useful for designing hand protections and generating hand models more accurately. Significant differences were identified between both aspects in almost all the lengths. Only the lengths of some distal phalanges seem to be equivalent.

This result reinforces the idea that hand anthropometry databases should explicitly state the aspect (dorsal or palmar) in which each dimension has been measured and those databases could be completed with dimensions from landmarks of both aspects, in order to be more useful for the design of hand protections.

\section{Acknowledgements}

We are grateful to Cristina Ponce and Evelyn Rosales for their help in data collection. We thank the Universitat Jaume I for the financial support through the project P1- 
1B2014-10 and the Ministerio de Economía y Competitividad de España and the European Union (European Regional Development Funds) through project DPI2014-52095-P.

\section{References}

Agnihotri, A. K., Agnihotri, S., Jeebun, N., \& Googoolye, K. (2008). Prediction of stature using hand dimensions. Journal of Forensic and Legal Medicine, 15(8), $479-482$.

Altman, D. G., \& Bland, J. M. (1983). Measurement in Medicine: the Analysis of Method Comparison Studies. The Statistician, 32, 307-317.

Armstrong, T. J., Best, C., Bae, S., Choi, J., Grieshaber, D. C., Park, D., ... Zhou, W. (2009). Development of a Kinematic Hand Model for Study and Design of Hose Installation. Lecture Notes in Computer Science, 5620, 85-94.

Buchholz, B., Armstrong, T. J., \& Goldstein, S. A. (1992). Anthropometric Data for Describing the Kinematics of the Human Hand. Ergonomics, 35(3), 261-273.

Burm, J. S., Chung, C. H., \& Oh, S. J. (1999). Fist position for skin grafting on the dorsal hand: I. Analysis of length of the dorsal hand surgery in hand positions. Plastic and Reconstructive Surgery, 104(5), 1350-1355.

Cakit, E., Durgun, B., Cetik, O., \& Yoldas, O. (2014). A Survey of Hand Anthropometry and Biomechanical Measurements of Dentistry Students in Turkey. Human Factors and Ergonomics in Manufacturing \& Service Industries, 24(6), $739-753$.

Carmona Benjumea, A. (2003). Aspectos antropométricos de la población laboral 
española aplicados al diseño industrial. Madrid: Instituto Nacional de Seguridad e Higiene en el Trabajo. Ministerio de Trabajo e inmigración.

Choi, H., Park, M. S., Nam, B., Lee, J., Kim, E., \& Lee, H.-M. (2011). Palm surface area database and estimation formula in Korean children using the alginate method. Applied Ergonomics, 42(6), 873-882.

Dianat, I., Haslegrave, C. M., \& Stedmon, A. W. (2012). Methodology for evaluating gloves in relation to the effects on hand performance capabilities: a literature review. Ergonomics, 55(11), 1429-1451.

García-Cáceres, R. G., Felknor, S., Córdoba, J. E., Caballero, J. P., \& Barrero, L. H. (2012). Hand anthropometry of the Colombian floriculture workers of the Bogota plateau. International Journal of Industrial Ergonomics, 42(2), 183-198.

Habibi, E., Soury, S., \& Zadeh, A. (2013). Precise Evaluation of Anthropometric 2D Software Processing of Hand in Comparison with Direct Method. Journal of Medical Signals and Sensors, 3(4), 256-261.

Harih, G., \& Dolšak, B. (2013). Tool-handle design based on a digital human hand model. International Journal of Industrial Ergonomics, 43(4), 288-295.

Harih, G., \& Dolšak, B. (2014). Comparison of subjective comfort ratings between anatomically shaped and cylindrical handles. Applied Ergonomics, 45(4), 943-954.

Hsu, Y.-W., \& Yu, C.-Y. (2010). Hand surface area estimation formula using 3D anthropometry. Journal of Occupational and Environmental Hygiene, 7(11), 633639.

Imrhan, S. N., Sarder, M. D., \& Mandahawi, N. (2009). Hand anthropometry in Bangladeshis living in America and comparisons with other populations. 
Ergonomics, 52(8), 987-998.

Ishak, N.-I., Hemy, N., \& Franklin, D. (2012a). Estimation of sex from hand and handprint dimensions in a Western Australian population. Forensic Science International, 221(1-3), 154.e1-154.e6.

Ishak, N.-I., Hemy, N., \& Franklin, D. (2012b). Estimation of stature from hand and handprint dimensions in a Western Australian population. Forensic Science International, 216(1-3), 199.e1-199.e7.

ISO 7250-1:2008. (2008). Basic human body measurements for technological design -Part 1: Body measurement definitions and landmarks.

Kanchan, T., \& Krishan, K. (2011). Anthropometry of hand in sex determination of dismembered remains - A review of literature. Journal of Forensic and Legal Medicine, 18(1), 14-17.

Krishan, K., \& Sharma, A. (2007). Estimation of stature from dimensions of hands and feet in a North Indian population. Journal of Forensic and Legal Medicine, 14(6), $327-332$.

Kwon, O., Jung, K., You, H., \& Kim, H. E. (2009). Determination of key dimensions for a glove sizing system by analyzing the relationships between hand dimensions. Applied Ergonomics, 40(4), 762-766.

Lee, K.-S., \& Jung, M.-C. (2015). Ergonomic evaluation of biomechanical hand function. Safety and Health at Work, 6(1), 9-17.

Li, Z., Chang, C.-C., Dempsey, P. G., Ouyang, L., \& Duan, J. (2008). Validation of a three-dimensional hand scanning and dimension extraction method with dimension data. Ergonomics, 51(11), 1672-1692. 
Mandahawi, N., Imrhan, S., Al-Shobaki, S., \& Sarder, B. (2008). Hand anthropometry survey for the Jordanian population. International Journal of Industrial Ergonomics, 38(11-12), 966-976.

Obi, O. F. (2016). Hand anthropometry survey of rural farm workers in south-eastern Nigeria. Ergonomics, 59(4), 603-611.

Okunribido, O. O. (2000). A survey of hand anthropometry of female rural farm workers in Ibadan, western Nigeria. Ergonomics, 43(2), 282-292.

Rogers, M. S., Barr, A. B., Kasemsontitum, B., \& Rempel, D. M. (2008). A threedimensional anthropometric solid model of the hand based on landmark measurements. Ergonomics, 51(4), 511-526.

Sancho-Bru, J. L. J. L., Pérez-González, A., Mora, M. C., León, B. E., Vergara, M., Iserte, J. L., ... Morales, A. (2011). Towards a Realistic and Self-Contained Biomechanical Model of the Hand. In V. Klika (Ed.), “Theoretical Biomechanics. ” https://doi.org/10.5772/19977

Sen, J., Kanchan, T., Ghosh, A., Mondal, N., \& Krishan, K. (2014). Estimation of stature from lengths of index and ring fingers in a North-eastern Indian population. Journal of Forensic and Legal Medicine, 22(1), 10-15.

Yu, A., Yick, K. L., Ng, S. P., \& Yip, J. (2013). 2D and 3D anatomical analyses of hand dimensions for custom-made gloves. Applied Ergonomics, 44(3), 381-392. 


\section{Tables}

Table 1. Descriptive statistics of the sample.

Table 2. Hand dimensions considered in the study. * Thumb Skin: Junction between palm and thumb at the Carpometacarpal joint of the thumb.

Table 3. Repeatability errors of the dimensions separately. Mean values of the 99 ANOVAs in mm (RMSE) and in ratio (RMSE/dimension). Values reported globally, and per method or per dimension.

Table 4. Descriptive Statistics for right-hand dorsal lengths (mm) of the sample. * Normally distributed dimension. $\mathrm{SD}=$ standard deviation; 5th, 95th $=5$ and 95 percentile values. Abbreviations of dimensions are shown in Table 2 and figures 5 and 6.

Table 5. Descriptive Statistics for right-hand palmar lengths $(\mathrm{mm})$ of the sample. * Normally distributed dimension. $\mathrm{SD}=$ standard deviation; 5th, 95 th $=5$ and 95 percentile values. Abbreviations of dimensions are shown in Table 2 and figures 5 and 6.

Table 6. Descriptive Statistics for right-hand breadths (mm) of the sample. * Normally distributed dimension. $\mathrm{SD}=$ standard deviation; 5 th, $95 \mathrm{th}=5$ and 95 percentile values Abbreviations of dimensions are shown in Table 2 and figures 5 and 6.

Table 7. Descriptive Statistics for right-hand depths $(\mathrm{mm})$ of the sample. * Normally distributed dimension. $\mathrm{SD}=$ standard deviation; 5 th, 95 th $=5$ and 95 percentile values. Abbreviations of dimensions are shown in Table 2 and figures 5 and 6.

Table 8. Results of the paired t-tests comparing hand lengths measured on the dorsal and the palmar view. Differences are considered as dimension in dorsal view - same dimension in palmar view), SD: standard deviation of differences, t: t-values of each 
test, $*$ : bilateral critical value $<0.05, * *$ : bilateral critical value $<0.01, \%$ Diff: ratio between the mean differences with respect to dorsal view dimension (mean differences / mean dorsal view dimension) in percentage. 


\begin{tabular}{|l|r|r|r|r|r|r|r|r|}
\cline { 2 - 10 } \multicolumn{1}{c|}{} & \multicolumn{4}{c|}{ Females (N=69) } & \multicolumn{4}{c|}{ Males (N=70) } \\
\cline { 2 - 10 } & Mean & \multicolumn{1}{c|}{ SD } & \multicolumn{1}{c|}{ Min. } & Max. & Mean & \multicolumn{1}{c|}{ SD } & Min. & Max. \\
\hline Age (years) & 34.3 & 11.87 & 18 & 68 & 36.7 & 11.21 & 20 & 65 \\
\hline Stature (mm) & 1622 & 64.7 & 1500 & 1750 & 177 & 71.6 & 1600 & 1930 \\
\hline Weight (kg) & 62 & 10.1 & 45 & 90 & 76.7 & 11.1 & 58 & 106 \\
\hline
\end{tabular}

Table 1. Descriptive statistics of the sample. 


\begin{tabular}{|c|c|c|c|c|c|}
\hline \multicolumn{6}{|c|}{ LENGTHS } \\
\hline Thumb & $\begin{array}{l}\text { L1DP_dv } \\
\text { L1DP_pv }\end{array}$ & $\begin{array}{l}\text { L1PP_dv } \\
\text { L1PP_pv }\end{array}$ & $\begin{array}{l}\text { L1MC_dv } \\
\text { L1MC_pv }\end{array}$ & & \\
\hline Index finger & $\begin{array}{l}\text { L2DP_dv } \\
\text { L2DP_pv }\end{array}$ & $\begin{array}{l}\text { L2MP_dv } \\
\text { L2MP_pv }\end{array}$ & $\begin{array}{l}\text { L2PP_dv } \\
\text { L2PP_pv }\end{array}$ & $\begin{array}{l}\text { L2MC_dv } \\
\text { L2MC_pv }\end{array}$ & \\
\hline Middle finger & $\begin{array}{l}\text { L3DP_dv } \\
\text { L3DP_pv }\end{array}$ & $\begin{array}{l}\text { L3MP_dv } \\
\text { L3MP_pv }\end{array}$ & $\begin{array}{l}\text { L3PP_dv } \\
\text { L3PP_pv }\end{array}$ & $\begin{array}{l}\text { L3MC_dv } \\
\text { L3MC_pv }\end{array}$ & \\
\hline Ring finger & $\begin{array}{l}\text { L4DP_dv } \\
\text { L4DP_pv }\end{array}$ & $\begin{array}{l}\text { L4MP_dv } \\
\text { L4MP_pv }\end{array}$ & $\begin{array}{l}\text { L4PP_dv } \\
\text { L4PP_pv }\end{array}$ & $\begin{array}{l}\text { L4MC_dv } \\
\text { L4MC_pv }\end{array}$ & \\
\hline Little finger & $\begin{array}{l}\text { L5DP_dv } \\
\text { L5DP_pv }\end{array}$ & $\begin{array}{l}\text { L5MP_dv } \\
\text { L5MP_pv }\end{array}$ & $\begin{array}{l}\text { L5PP_dv } \\
\text { L5PP_pv }\end{array}$ & $\begin{array}{l}\text { L5MC_dv } \\
\text { L5MC_pv }\end{array}$ & \\
\hline Thumb skin * & L1S_dv & & & & \\
\hline Whole Hand & $\begin{array}{l}\text { LH_dv } \\
\text { LH_pv }\end{array}$ & & & & \\
\hline \multicolumn{6}{|c|}{ BREADTHS } \\
\hline Thumb & B1DP & B1IP & B1PP & B1MCP & \\
\hline Index finger & B2DP & B2DIP & B2MP & B2PIP & B2PP \\
\hline Middle finger & B3DP & B3DIP & B3MP & B3PIP & B3PP \\
\hline Ring finger & B4DP & B4DIP & B4MP & B4PIP & B4PP \\
\hline Little finger & B5DP & B5DIP & B5MP & B5PIP & B5PP \\
\hline $\begin{array}{l}\text { Palm (knuckles } \\
\text { level) }\end{array}$ & $\mathrm{BP}$ & & & & \\
\hline Wrist & $\mathrm{BW}$ & & & & \\
\hline \multicolumn{6}{|c|}{ DEPTHS } \\
\hline Thumb & D1DP & D1IP & D1PP & D1MCP & \\
\hline Index finger & D2DP & D2DIP & D2MP & D2PIP & $\mathrm{D} 2 \mathrm{PP}$ \\
\hline Middle finger & D3DP & D3DIP & D3MP & D3PIP & $\mathrm{D} 3 \mathrm{PP}$ \\
\hline Ring finger & D4DP & D4DIP & D4MP & D4PIP & $\mathrm{D} 4 \mathrm{PP}$ \\
\hline Little finger & D5DP & D5DIP & D5MP & D5PIP & D5PP \\
\hline Knuckles & $\mathrm{D} 2 \mathrm{MCP}$ & D3MCP & D4MCP & D5MCP & \\
\hline Palm centre & DPC & & & & \\
\hline Thumb base & DPB1 & & & & \\
\hline Little finger base & DPB5 & & & & \\
\hline Wrist & DW & & & & \\
\hline
\end{tabular}

Table 2. Hand dimensions considered in the study. * Thumb Skin: Junction between palm and thumb at the Carpometacarpal joint of the thumb. 


\begin{tabular}{lrr} 
& RMSE (mm) & Ratio \\
Global & 0,98 & $3,2 \%$ \\
\hline Photographs & 1,06 & $3,0 \%$ \\
Manual & 0,72 & $4,1 \%$ \\
\hline Lengths & 1,52 & $3,3 \%$ \\
Breadths & 0,51 & $2,5 \%$ \\
Depths & 0,95 & $3,2 \%$ \\
\hline Lengths_pv & 1,58 & $3,3 \%$ \\
Lengths_dv & 1,47 & $3,3 \%$
\end{tabular}

Table 3. Repeatability errors of the dimensions separately. Mean values of the 99 ANOVAs in $\mathrm{mm}$ (RMSE) and in ratio (RMSE/dimension). Values reported globally, and per method or per dimension. 
DORSAL LENGTHS

\begin{tabular}{|c|c|c|c|c|c|c|c|c|c|c|c|c|c|c|}
\hline & \multicolumn{5}{|c|}{ Females } & \multicolumn{5}{|c|}{ Males } & \multicolumn{4}{|c|}{ Females and males jointly } \\
\hline & $\mathrm{N}$ & Mean & SD & 5 th & 95th & $\mathrm{N}$ & Mean & SD & 5 th & 95th & Mean & SD & 5 th & 95th \\
\hline L1DP_dv & 69 & $28.8^{*}$ & 2.61 & 24.0 & 32.5 & 70 & 32.5 & 2.30 & 29.0 & 37.0 & 30.6 & 3.07 & 26.0 & 36.0 \\
\hline L1PP_dv & 69 & 31.9 & 3.52 & 27.0 & 37.5 & 70 & $33.9^{*}$ & 3.24 & 28.1 & 40.0 & 32.9 & 3.51 & 27.0 & 38.0 \\
\hline L1MC_dv & 69 & $55.0 *$ & 6.06 & 45.0 & 66.5 & 70 & $59.4^{*}$ & 7.69 & 46.0 & 71.0 & 57.2 & 7.26 & 46.0 & 70.0 \\
\hline L2DP_dv & 69 & 23.5 & 1.87 & 20.5 & 27.0 & 70 & 25.5 & 2.02 & 22.0 & 29.0 & 24.5 & 2.18 & 21.0 & 28.0 \\
\hline L2MP_dv & 69 & 24.8 & 2.41 & 21.0 & 29.5 & 70 & 26.4 & 2.52 & 22.0 & 30.5 & 25.6 & 2.60 & 21.0 & 30.0 \\
\hline L2PP_dv & 69 & $43.5^{*}$ & 3.79 & 39.0 & 49.5 & 70 & $47.0^{*}$ & 3.30 & 42.0 & 53.0 & $45.3^{*}$ & 3.96 & 39.0 & 52.0 \\
\hline L2MC_dv & 69 & $77.9 *$ & 5.83 & 67.5 & 89.0 & 70 & 83.8 & 7.07 & 72.6 & 93.9 & 80.9 & 7.12 & 69.0 & 93.0 \\
\hline L3DP_dv & 69 & 25.6 & 2.12 & 22.0 & 29.5 & 70 & 27.4 & 2.49 & 23.6 & 32.0 & 26.5 & 2.47 & 22.0 & 31.0 \\
\hline L3MP_dv & 69 & $29.4^{*}$ & 2.64 & 25.0 & 34.0 & 70 & 31.6 & 2.39 & 27.6 & 36.0 & 30.6 & 2.74 & 26.0 & 35.0 \\
\hline L3PP_dv & 69 & 48.8 & 3.48 & 44.0 & 54.5 & 70 & $52.4^{*}$ & 3.25 & 46.6 & 58.0 & 50.6 & 3.79 & 45.0 & 57.0 \\
\hline L3MC_dv & 69 & $73.7^{*}$ & 5.28 & 66.0 & 83.5 & 70 & $79.8^{*}$ & 6.57 & 68.6 & 90.5 & $76.8^{*}$ & 6.69 & 66.0 & 88.0 \\
\hline L4DP_dv & 69 & 25.6 & 1.92 & 22.0 & 29.0 & 70 & 27.1 & 2.20 & 24.0 & 31.0 & 26.4 & 2.19 & 23.0 & 30.0 \\
\hline L4MP_dv & 69 & 27.3 & 2.60 & 23.0 & 31.5 & 70 & 29.6 & 2.49 & 25.0 & 34.0 & 28.4 & 2.79 & 24.0 & 33.0 \\
\hline L4PP_dv & 69 & 44.2 & 3.47 & 39.5 & 50.0 & 70 & 47.4 & 3.20 & 41.0 & 52.0 & 45.8 & 3.68 & 41.0 & 52.0 \\
\hline L4MC_dv & 69 & 69.0* & 5.10 & 60.5 & 78.5 & 70 & $74.8^{*}$ & 6.52 & 64.1 & 84.9 & 72.0 & 6.52 & 62.0 & 83.0 \\
\hline L5DP_dv & 69 & 22.6 & 2.43 & 19.0 & 26.0 & 70 & 23.9 & 2.15 & 20.6 & 28.0 & 23.2 & 2.38 & 20.0 & 27.0 \\
\hline L5MP_dv & 69 & 18.5 & 2.29 & 14.5 & 22.0 & 70 & $20.9 *$ & 2.19 & 17.0 & 24.5 & 19.7 & 2.53 & 16.0 & 24.0 \\
\hline L5PP_dv & 69 & $34.7^{*}$ & 3.07 & 30.5 & 39.0 & 70 & $37.4^{*}$ & 3.29 & 32.0 & 43.0 & 36.1 & 3.44 & 31.0 & 42.0 \\
\hline L5MC_dv & 69 & 63.9 & 5.27 & 55.5 & 72.5 & 70 & 69.* & 6.79 & 57.6 & 80.5 & 66.5 & 6.57 & 56.0 & 78.0 \\
\hline LS1 & 55 & 65.7 & 5.36 & 58.0 & 77.2 & 61 & $71.6^{*}$ & 7.65 & 59.1 & 82.9 & 68.8 & 7.28 & 59.0 & 81.2 \\
\hline LH_dv & 69 & $177.4^{*}$ & 9.78 & 163.0 & 195.0 & 70 & $190.7^{*}$ & 9.74 & 176.0 & 206.0 & $184.1^{*}$ & 11.83 & 163.0 & 203.0 \\
\hline
\end{tabular}

Table 4. Descriptive Statistics for right-hand dorsal lengths $(\mathrm{mm})$ of the sample. *

Normally distributed dimension. $\mathrm{SD}=$ standard deviation; 5th, $95 \mathrm{th}=5$ and 95 percentile values. Abbreviations of dimensions are shown in Table 2 and figures 5 and 6. 
PALMAR LENGTHS

\begin{tabular}{|c|c|c|c|c|c|c|c|c|c|c|c|c|c|c|}
\hline & \multicolumn{5}{|c|}{ Females } & \multicolumn{5}{|c|}{ Males } & \multicolumn{4}{|c|}{ Females and males jointly } \\
\hline & $\mathrm{N}$ & Mean & SD & 5th & 95th & $\mathrm{N}$ & Mean & SD & 5th & 95th & Mean & SD & 5th & 95th \\
\hline L1DP_pv & 69 & 28.9 & 3.74 & 21.5 & 34.0 & 70 & $31.1^{*}$ & 4.04 & 23.1 & 37.0 & 30.0 & 4.03 & 22.0 & 36.0 \\
\hline L1PP_pv & 69 & 29.8 & 3.69 & 23.5 & 35.0 & 70 & 32.6 & 4.12 & 26.1 & 38.5 & 31.2 & 4.14 & 24.0 & 38.0 \\
\hline L1MC_pv & 69 & $60.3^{*}$ & 5.37 & 50.5 & 69.0 & 70 & $64.7^{*}$ & 6.75 & 52.6 & 76.5 & $62.5^{*}$ & 6.47 & 51.0 & 73.0 \\
\hline L2DP_pv & 69 & 25.2 & 2.07 & 21.5 & 28.0 & 70 & 26.6 & 2.01 & 23.1 & 30.0 & 25.9 & 2.15 & 22.0 & 29.0 \\
\hline L2MP_pv & 69 & 21.2 & 2.14 & 17.0 & 24.0 & 70 & 22.1 & 1.99 & 19.0 & 25.0 & 21.7 & 2.12 & 18.0 & 25.0 \\
\hline L2PP_pv & 69 & 24.8 & 2.63 & 21.0 & 29.5 & 70 & $25.8^{*}$ & 2.44 & 21.6 & 30.0 & 25.3 & 2.58 & 21.0 & 30.0 \\
\hline L2MC_pv & 69 & $104.3^{*}$ & 6.34 & 94.5 & 114.5 & 70 & 112.9* & 5.92 & 102.1 & 122.0 & 108.6* & 7.48 & 96.0 & 120.0 \\
\hline L3DP_pv & 69 & 26.3 & 2.20 & 22.5 & 30.5 & 70 & 27.5 & 2.10 & 23.6 & 31.0 & 26.9 & 2.23 & 23.0 & 31.0 \\
\hline L3MP_pv & 69 & 24.2 & 2.24 & 20.5 & 28.0 & 70 & 25.6 & 2.21 & 21.0 & 29.0 & 24.9 & 2.34 & 21.0 & 29.0 \\
\hline L3PP_pv & 69 & $27.9 *$ & 2.61 & 23.5 & 32.5 & 70 & 29.2 & 2.31 & 25.6 & 33.0 & 28.6 & 2.54 & 24.0 & 33.0 \\
\hline L3MC_pv & 69 & 106. 8* & 6.33 & 97.0 & 116.5 & 70 & $115.4^{*}$ & 5.63 & 105.6 & 124.0 & 111.1 & 7.36 & 98.0 & 123.0 \\
\hline L4DP_pv & 69 & 25.4 & 2.19 & 21.5 & 29.5 & 70 & 27.0 & 1.97 & 24.0 & 30.5 & 26.2 & 2.22 & 23.0 & 30.0 \\
\hline L4MP_pv & 69 & 22.5 & 2.20 & 19.0 & 26.0 & 70 & 23.6 & 2.04 & 20.6 & 27.5 & 23.0 & 2.18 & 20.0 & 26.0 \\
\hline L4PP_pv & 69 & 24.7 & 2.58 & 20.5 & 29.0 & 70 & 26.1 & 2.24 & 22.0 & 30.0 & 25.4 & 2.51 & 21.0 & 30.0 \\
\hline L4MC_pv & 69 & $102.6^{*}$ & 5.87 & 92.5 & 111.0 & 70 & $110.9 *$ & 5.33 & 102.0 & 119.5 & 106.8 & 6.95 & 95.0 & 118.0 \\
\hline L5DP_pv & 69 & 22.9 & 1.99 & 19.0 & 26.0 & 70 & 24.7 & 2.08 & 21.0 & 28.0 & 23.8 & 2.24 & 20.0 & 27.0 \\
\hline L5MP_pv & 69 & 15.8 & 2.11 & 13.0 & 20.0 & 70 & 17.3 & 1.96 & 14.0 & 20.5 & 16.5 & 2.16 & 13.0 & 20.0 \\
\hline L5PP_pv & 69 & 19.4 & 2.42 & 16.0 & 24.5 & 70 & 20.6 & 2.66 & 17.0 & 26.0 & 20.0 & 2.61 & 17.0 & 25.0 \\
\hline L5MC_pv & 69 & 91.1* & 5.95 & 81.0 & 100.5 & 70 & $99.3^{*}$ & 5.48 & 91.6 & 108.5 & $95.2 *$ & 7.03 & 82.0 & 107.0 \\
\hline LH_pv & 69 & $184.5^{*}$ & 10.35 & 168.5 & 201.0 & 70 & $197.6^{*}$ & 8.93 & 184.0 & 210.9 & 191.1 & 11.66 & 172.0 & 209.0 \\
\hline
\end{tabular}

Table 5. Descriptive Statistics for right-hand palmar lengths $(\mathrm{mm})$ of the sample. *

Normally distributed dimension. $\mathrm{SD}=$ standard deviation; 5 th, 95 th $=5$ and 95 percentile values. Abbreviations of dimensions are shown in Table 2 and figures 5 and 6. 
BREADTHS

\begin{tabular}{|c|c|c|c|c|c|c|c|c|c|c|c|c|c|c|}
\hline & \multicolumn{5}{|c|}{ Females } & \multicolumn{5}{|c|}{ Males } & \multicolumn{4}{|c|}{ Females and males jointly } \\
\hline & $\mathrm{N}$ & Mean & SD & 5 th & 95th & $\mathrm{N}$ & Mean & SD & 5 th & 95th & Mean & SD & 5th & 95th \\
\hline B1DP & 69 & 20.0 & 1.72 & 18.0 & 23.0 & 70 & 22.9 & 1.71 & 20.0 & 26.0 & 21.5 & 2.24 & 18.0 & 26.0 \\
\hline B1IP & 69 & 20.3 & 1.62 & 18.0 & 23.5 & 70 & 23.2 & 1.78 & 20.0 & 26.0 & 21.7 & 2.23 & 18.0 & 26.0 \\
\hline B1PP & 69 & 20.4 & 2.25 & 17.5 & 25.0 & 70 & 23.0 & 2.21 & 19.6 & 27.5 & 21.7 & 2.57 & 18.0 & 26.0 \\
\hline B1MCP & 69 & 24.8 & 2.25 & 21.0 & 29.0 & 70 & 27.3 & 2.58 & 23.1 & 31.0 & 26.0 & 2.71 & 21.0 & 31.0 \\
\hline B2DP & 69 & 15.5 & 1.23 & 14.0 & 17.0 & 70 & 17.9 & 1.53 & 15.6 & 20.0 & 16.7 & 1.84 & 14.0 & 20.0 \\
\hline B2DIP & 69 & 16.4 & 1.20 & 14.5 & 18.5 & 70 & 18.6 & 1.39 & 17.0 & 21.0 & 17.5 & 1.72 & 15.0 & 20.0 \\
\hline $\mathrm{B} 2 \mathrm{MP}$ & 69 & 17.5 & 1.21 & 16.0 & 20.0 & 70 & 20.0 & 1.40 & 18.0 & 22.0 & 18.8 & 1.82 & 16.0 & 22.0 \\
\hline B2PIP & 69 & 19.3 & 1.29 & 17.0 & 21.5 & 70 & 21.9 & 1.45 & 20.0 & 24.0 & 20.6 & 1.92 & 18.0 & 24.0 \\
\hline B2PP & 69 & 21.0 & 1.70 & 18.0 & 24.0 & 70 & 23.7 & 1.73 & 21.0 & 27.0 & 22.4 & 2.16 & 19.0 & 26.0 \\
\hline B3DP & 69 & 15.4 & 1.33 & 13.0 & 18.0 & 70 & 17.5 & 1.68 & 14.6 & 20.0 & 16.5 & 1.83 & 13.0 & 20.0 \\
\hline B3DIP & 69 & 15.9 & 1.19 & 14.0 & 18.0 & 70 & 17.8 & 1.39 & 15.6 & 20.0 & 16.8 & 1.62 & 14.0 & 20.0 \\
\hline B3MP & 69 & 16.5 & 1.52 & 14.0 & 19.5 & 70 & 18.7 & 1.77 & 16.0 & 21.5 & 17.6 & 1.99 & 14.0 & 21.0 \\
\hline B3PIP & 69 & 18.3 & 1.59 & 16.0 & 21.5 & 70 & 20.5 & 1.79 & 18.0 & 23.5 & 19.4 & 2.02 & 17.0 & 23.0 \\
\hline B3PP & 69 & 17.7 & 1.69 & 15.0 & 21.0 & 70 & 19.5 & 2.06 & 16.0 & 23.0 & 18.6 & 2.08 & 15.0 & 22.0 \\
\hline B4DP & 69 & 14.8 & 1.22 & 13.0 & 17.0 & 70 & 16.6 & 1.49 & 14.0 & 19.0 & 15.7 & 1.64 & 13.0 & 18.0 \\
\hline B4DIP & 69 & 14.9 & 1.16 & 13.0 & 17.0 & 70 & 16.7 & 1.37 & 14.0 & 19.0 & 15.8 & 1.55 & 13.0 & 18.0 \\
\hline B4MP & 69 & 15.2 & 1.44 & 13.0 & 18.0 & 70 & 16.9 & 1.71 & 14.0 & 19.5 & 16.1 & 1.79 & 13.0 & 19.0 \\
\hline B4PIP & 69 & 17.1 & 1.39 & 15.0 & 20.0 & 70 & 19.3 & 1.77 & 16.0 & 22.0 & 18.2 & 1.92 & 15.0 & 21.0 \\
\hline B4PP & 69 & 16.7 & 1.56 & 14.0 & 19.5 & 70 & 18.4 & 2.11 & 14.6 & 22.0 & 17.6 & 2.04 & 14.0 & 21.0 \\
\hline B5DP & 69 & 12.9 & 1.29 & 11.0 & 15.5 & 70 & 15.0 & 1.62 & 12.0 & 18.0 & 14.0 & 1.79 & 11.0 & 17.0 \\
\hline B5DIP & 69 & 13.4 & 1.03 & 12.0 & 15.0 & 70 & 15.2 & 1.26 & 13.0 & 17.0 & 14.3 & 1.46 & 12.0 & 17.0 \\
\hline B5MP & 69 & 13.7 & 1.30 & 12.0 & 16.0 & 70 & 15.6 & 1.43 & 13.0 & 18.0 & 14.6 & 1.67 & 12.0 & 17.0 \\
\hline B5PIP & 69 & 15.0 & 1.20 & 13.0 & 17.0 & 70 & 16.9 & 1.41 & 15.0 & 19.0 & 15.9 & 1.61 & 14.0 & 19.0 \\
\hline B5PP & 69 & 15.6 & 1.62 & 13.0 & 18.5 & 70 & $17.2^{*}$ & 2.18 & 13.6 & 21.0 & 16.4 & 2.09 & 13.0 & 20.0 \\
\hline BP & 69 & 74.8 & 3.14 & 70.0 & 80.5 & 70 & 84.9* & 4.28 & 76.6 & 92.0 & 79.9 & 6.29 & 70.0 & 90.0 \\
\hline BW & 69 & 51.5 & 3.71 & 45.5 & 58.0 & 70 & $57.8^{*}$ & 3.42 & 52.0 & 63.0 & 54.7 & 4.74 & 47.0 & 63.0 \\
\hline
\end{tabular}


Table 6. Descriptive Statistics for right-hand breadths $(\mathrm{mm})$ of the sample. * Normally distributed dimension. $\mathrm{SD}=$ standard deviation; 5 th, 95 th $=5$ and 95 percentile values. Abbreviations of dimensions are shown in Table 2 and figures 5 and 6. 
DEPTHS

\begin{tabular}{|c|c|c|c|c|c|c|c|c|c|c|c|c|c|c|}
\hline & \multicolumn{5}{|c|}{ Females } & \multicolumn{5}{|c|}{ Males } & \multicolumn{4}{|c|}{ Females and males jointly } \\
\hline & $\mathrm{N}$ & Mean & SD & 5th & 95th & $\mathrm{N}$ & Mean & SD & 5th & 95th & Mean & SD & 5th & 95th \\
\hline D1DP & 69 & 15.2 & 1.64 & 13.0 & 18.0 & 70 & 17.0 & 2.20 & 13.0 & 21.5 & 16.1 & 2.14 & 13.0 & 20.0 \\
\hline D1IP & 69 & 18.4 & 1.32 & 16.0 & 21.0 & 70 & 21.1 & 1.72 & 18.0 & 24.5 & 19.8 & 2.03 & 17.0 & 23.0 \\
\hline D1PP & 69 & 19.8 & 1.61 & 17.0 & 23.0 & 70 & 22.6 & 1.86 & 20.0 & 26.0 & 21.2 & 2.23 & 18.0 & 25.0 \\
\hline D1MCP & 69 & 23.1 & 1.84 & 20.0 & 26.0 & 70 & 26.1 & 2.53 & 22.6 & 31.0 & 24.6 & 2.68 & 21.0 & 30.0 \\
\hline D2DP & 69 & 12.5 & 1.07 & 11.0 & 14.5 & 70 & 14.1 & 1.50 & 12.0 & 16.0 & 13.3 & 1.55 & 11.0 & 16.0 \\
\hline D2DIP & 69 & 13.7 & 1.11 & 12.0 & 16.0 & 70 & 15.7 & 1.48 & 14.0 & 18.0 & 14.7 & 1.65 & 12.0 & 17.0 \\
\hline D2MP & 69 & 15.5 & 1.08 & 14.0 & 18.0 & 70 & 17.7 & 1.79 & 16.0 & 20.0 & 16.6 & 1.86 & 14.0 & 20.0 \\
\hline D2PIP & 69 & 17.6 & 1.20 & 16.0 & 20.0 & 70 & 20.3 & 2.03 & 18.0 & 23.0 & 19.0 & 2.13 & 16.0 & 22.0 \\
\hline D2PP & 69 & 20.1 & 1.74 & 17.5 & 23.0 & 70 & 22.6 & 2.32 & 20.0 & 25.9 & 21.4 & 2.39 & 18.0 & 25.0 \\
\hline D3DP & 69 & 11.4 & 1.35 & 10.0 & 14.0 & 70 & 12.2 & 1.60 & 10.0 & 15.5 & 11.8 & 1.52 & 10.0 & 15.0 \\
\hline D3DIP & 69 & 11.8 & 0.99 & 11.0 & 14.0 & 70 & 13.5 & 1.27 & 12.0 & 16.0 & 12.7 & 1.42 & 11.0 & 15.0 \\
\hline D3MP & 69 & 13.1 & 1.26 & 11.0 & 15.5 & 70 & 15.1 & 1.53 & 13.0 & 18.0 & 14.1 & 1.71 & 12.0 & 17.0 \\
\hline D3PIP & 69 & 15.6 & 1.12 & 14.0 & 17.5 & 70 & 17.5 & 1.52 & 15.0 & 20.0 & 16.6 & 1.66 & 14.0 & 20.0 \\
\hline D3PP & 69 & 16.3 & 1.63 & 14.0 & 20.0 & 70 & 18.3 & 1.83 & 15.0 & 21.5 & 17.3 & 2.00 & 14.0 & 20.1 \\
\hline D4DP & 69 & 10.8 & 1.43 & 8.0 & 13.5 & 70 & 11.6 & 1.44 & 10.0 & 14.0 & 11.2 & 1.49 & 9.0 & 14.0 \\
\hline D4DIP & 69 & 11.0 & 0.86 & 10.0 & 12.5 & 70 & 12.6 & 1.08 & 11.0 & 15.0 & 11.8 & 1.25 & 10.0 & 14.0 \\
\hline D4MP & 69 & 12.2 & 1.20 & 10.5 & 14.0 & 70 & 14.1 & 1.57 & 11.6 & 16.5 & 13.2 & 1.68 & 11.0 & 16.0 \\
\hline D4PIP & 69 & 14.4 & 1.18 & 13.0 & 16.0 & 70 & 16.4 & 1.45 & 14.0 & 19.0 & 15.4 & 1.65 & 13.0 & 18.0 \\
\hline D4PP & 69 & 15.1 & 1.50 & 13.0 & 18.0 & 70 & 17.2 & 1.88 & 14.0 & 21.0 & 16.2 & 1.99 & 13.0 & 20.0 \\
\hline D5DP & 69 & 9.6 & 1.01 & 8.0 & 11.0 & 70 & 10.4 & 1.37 & 8.0 & 12.6 & 10.0 & 1.26 & 8.0 & 12.0 \\
\hline D5DIP & 69 & 10.2 & 0.83 & 9.0 & 11.5 & 70 & 11.4 & 1.05 & 10.0 & 13.0 & 10.8 & 1.12 & 9.0 & 13.0 \\
\hline D5MP & 69 & 11.2 & 0.92 & 10.0 & 13.0 & 70 & 12.8 & 1.26 & 11.0 & 15.0 & 12.0 & 1.37 & 10.0 & 14.0 \\
\hline D5PIP & 69 & 12.5 & 1.11 & 11.0 & 14.0 & 70 & 14.4 & 1.08 & 12.6 & 16.0 & 13.5 & 1.47 & 11.0 & 16.0 \\
\hline D5PP & 69 & 13.1 & 1.37 & 11.0 & 16.0 & 70 & 15.4 & 1.48 & 13.0 & 18.0 & 14.3 & 1.85 & 11.0 & 17.0 \\
\hline $\mathrm{D} 2 \mathrm{MCP}$ & 20 & 23.9 & 1.31 & 22.0 & 26.0 & 40 & 26.6 & 1.32 & 25.0 & 29.0 & 25.7 & 1.84 & 22.1 & 28.0 \\
\hline D3MCP & 69 & 23.5 & 1.88 & 20.5 & 26.0 & 70 & 27.5 & 2.18 & 23.6 & 31.0 & 25.5 & 2.85 & 21.0 & 30.0 \\
\hline D4MCP & 20 & 22.3 & 1.38 & 21.0 & 26.0 & 40 & 25.7 & 1.81 & 23.0 & 29.0 & 24.5 & 2.30 & 21.0 & 28.0 \\
\hline D5MCP & 20 & 20.3 & 1.56 & 18.0 & 23.9 & 40 & $23.7^{*}$ & 2.08 & 20.0 & 27.9 & $22.5^{*}$ & 2.49 & 18.1 & 26.0 \\
\hline
\end{tabular}


DEPTHS

\begin{tabular}{|l|r|r|r|r|r|r|r|r|r|r|r|r|r|r|}
\cline { 2 - 14 } & \multicolumn{4}{|c|}{ Females } & \multicolumn{5}{c|}{ Males } & \multicolumn{3}{c|}{ Females and males jointly } \\
\cline { 2 - 13 } & N & Mean & SD & 5 th & 95 th & N & Mean & SD & 5 th & 95 th & Mean & SD & 5 th & 95 th \\
\hline DPC & 69 & 25.5 & 2.23 & 22.0 & 29.5 & 70 & 29.7 & 3.63 & 21.6 & 35.0 & 27.6 & 3.68 & 22.0 & 34.0 \\
\hline DPB1 & 69 & 29.6 & 3.25 & 25.0 & 37.0 & 70 & 34.0 & 3.94 & 28.1 & 41.0 & $31.8^{*}$ & 4.21 & 26.0 & 40.0 \\
\hline DPB5 & 20 & 28.1 & 3.28 & 24.1 & 35.0 & 40 & $32.8^{*}$ & 3.48 & 26.1 & 39.0 & 31.2 & 4.08 & 25.0 & 38.0 \\
\hline DW & 69 & 34.1 & 2.42 & 30.0 & 38.5 & 70 & 38.9 & 4.05 & 32.6 & 44.0 & 36.5 & 4.12 & 31.0 & 43.0 \\
\hline
\end{tabular}

Table 7. Descriptive Statistics for right-hand depths $(\mathrm{mm})$ of the sample. * Normally distributed dimension. $\mathrm{SD}=$ standard deviation; 5th, 95 th $=5$ and 95 percentile values. Abbreviations of dimensions are shown in Table 2 and figures 5 and 6. 


\begin{tabular}{|c|c|c|c|c|c|c|c|c|c|c|c|c|}
\hline & \multicolumn{4}{|c|}{ Females } & \multicolumn{4}{|c|}{ Males } & \multicolumn{4}{|c|}{ Females and males jointly } \\
\hline$d v-p v$ & Mean & SD & $\mathrm{t}$ & \%Diff & Mean & SD & $\mathrm{t}$ & \%Diff & Mean & SD & $\mathrm{t}$ & $\%$ Diff \\
\hline L1DP & -0.1 & 3.59 & -0.30 & -0.45 & 1.4 & 3.82 & $3.04^{*}$ & 4.25 & 0.6 & 3.77 & 1.98 & 2.06 \\
\hline L1PP & 2.1 & 3.95 & $4.42^{*}$ & 6.58 & 1.3 & 4.51 & 2.36 & 3.75 & 1.7 & 4.25 & $4.67^{*}$ & 5.14 \\
\hline L1MC & -5.4 & 6.14 & $-7.26^{*}$ & -9.75 & -5.3 & 6.15 & $-7.17^{*}$ & -8.87 & -5.3 & 6.12 & $-10.24^{*}$ & -9.30 \\
\hline L2DP & -1.7 & 1.69 & $-8.57^{*}$ & -7.41 & -1.1 & 1.64 & $-5.82^{*}$ & -4.48 & -1.4 & 1.69 & $-10.06^{*}$ & -5.88 \\
\hline L2MP & 3.6 & 2.13 & $14.08^{*}$ & 14.57 & 4.3 & 2.02 & $17.79^{*}$ & 16.23 & 4.0 & 2.09 & $22.25^{*}$ & 15.43 \\
\hline L2PP & 18.7 & 3.58 & $43.45^{*}$ & 43.05 & 21.2 & 3.09 & $57.41^{*}$ & 45.14 & 20.0 & 3.56 & $66.13^{*}$ & 44.15 \\
\hline L2MC & -26.4 & 5.79 & $-37.95^{*}$ & -33.96 & -29.1 & 5.96 & $-40.86^{*}$ & -34.73 & -27.8 & 6.00 & $-54.57^{*}$ & -34.36 \\
\hline L3DP & -0.7 & 1.93 & -2.93 & -2.70 & -0.1 & 2.12 & -0.34 & -0.29 & -0.4 & 2.04 & -2.20 & -1.43 \\
\hline L3MP & 5.3 & 2.34 & $18.65^{*}$ & 17.87 & 6.0 & 2.45 & $20.49^{*}$ & 18.96 & 5.6 & 2.42 & $27.48^{*}$ & 18.46 \\
\hline L3PP & 20.9 & 3.40 & $51.17^{*}$ & 42.87 & 23.2 & 2.94 & $65.86^{*}$ & 44.25 & 22.1 & 3.36 & $77.46^{*}$ & 43.59 \\
\hline L3MC & -33.1 & 6.32 & $-43.48^{*}$ & -44.88 & -35.6 & 6.31 & $-47.20^{*}$ & -44.57 & -34.3 & 6.41 & $-63.13^{*}$ & -44.73 \\
\hline L4DP & 0.2 & 1.90 & 0.89 & 0.78 & 0.1 & 1.85 & 0.52 & 0.41 & 0.2 & 1.87 & 1.00 & 0.61 \\
\hline L4MP & 4.8 & 2.16 & $18.29^{*}$ & 17.47 & 6.0 & 2.16 & $23.33^{*}$ & 20.34 & 5.4 & 2.24 & $28.35^{*}$ & 18.93 \\
\hline L4PP & 19.5 & 3.43 & $47.23^{*}$ & 44.10 & 21.2 & 3.11 & $57.08^{*}$ & 44.87 & 20.4 & 3.38 & $71.11^{*}$ & 44.49 \\
\hline L4MC & -33.6 & 5.92 & $-47.10^{*}$ & -48.64 & -36.0 & 6.42 & $-46.96^{*}$ & -48.17 & -34.8 & 6.28 & $-65.38^{*}$ & -48.39 \\
\hline L5DP & -0.3 & 2.35 & -1.02 & -1.28 & -0.8 & 2.04 & $-3.41^{*}$ & -3.47 & -0.6 & 2.21 & $-3.00^{*}$ & -2.45 \\
\hline L5MP & 2.7 & 2.13 & $10.45^{*}$ & 14.50 & 3.6 & 1.88 & $15.99^{*}$ & 17.21 & 3.1 & 2.05 & $18.03^{*}$ & 15.96 \\
\hline L5PP & 15.3 & 3.03 & $42.04^{*}$ & 44.10 & 16.7 & 3.55 & $39.46^{*}$ & 44.80 & 16.0 & 3.37 & $56.18^{*}$ & 44.48 \\
\hline L5MC & -27.2 & 6.29 & $-35.90^{*}$ & -42.53 & -30.3 & 7.13 & $-35.62^{*}$ & -44.00 & -28.8 & 6.89 & $-49.26^{*}$ & -43.30 \\
\hline LH & -7.1 & 7.53 & $-7.83^{*}$ & -4.00 & -6.8 & 7.25 & $-7.86^{*}$ & -3.57 & -7.0 & 7.37 & $-11.13^{*}$ & -3.78 \\
\hline Max. & 20.9 & 7.54 & & & 23.2 & 7.25 & & & 22.1 & 7.37 & & \\
\hline Min. & -33.6 & 1.69 & & & -36.0 & 1.64 & & & -34.8 & 1.69 & & \\
\hline Mean & -2.1 & 3.78 & & & -2.0 & 3.82 & & & -2.1 & 3.87 & & \\
\hline
\end{tabular}

Table 8. Results of the paired t-tests comparing hand lengths measured on the dorsal and the palmar view. Differences are considered as dimension in dorsal view - same dimension in palmar view), SD: standard deviation of differences, t: t-values of each 
test, *: bilateral critical value $<0.01, \%$ Diff: ratio between the mean differences with respect to dorsal view dimension (mean differences / mean dorsal view dimension) in percentage. 


\section{Figures}

Figure 1. Marking limits of phalanges and metacarpals: from a) to e) limits of phalanges; f) and g) limits of hand (metacarpals with the wrist); h) limit of each metacarpal (direction).

Figure 2. Example of the 5 photographs of the hand and fingers with landmarks for one subject. A: dorsal view of the whole hand, B: palmar view of the whole hand, C: lateral view of thumb, D: dorsal view of thumb, E: lateral view of index.

Figure 3. Example of the body and arm postures. From left to right: dorsal and palmar view of the whole hand, lateral and dorsal view of thumb, and lateral view of index. Figure 4. Examples of some hand depths measured with a spreading calliper.

Figure 5. Hand measurements taken from photographs: all lengths and breadths, and some depths.

Figure 6. Points where the hand depths were measured manually. Note that depths related to the thumb (DPB1, D1MCP) were measured across the thumb (see Figure 4), not perpendicular to this image. 


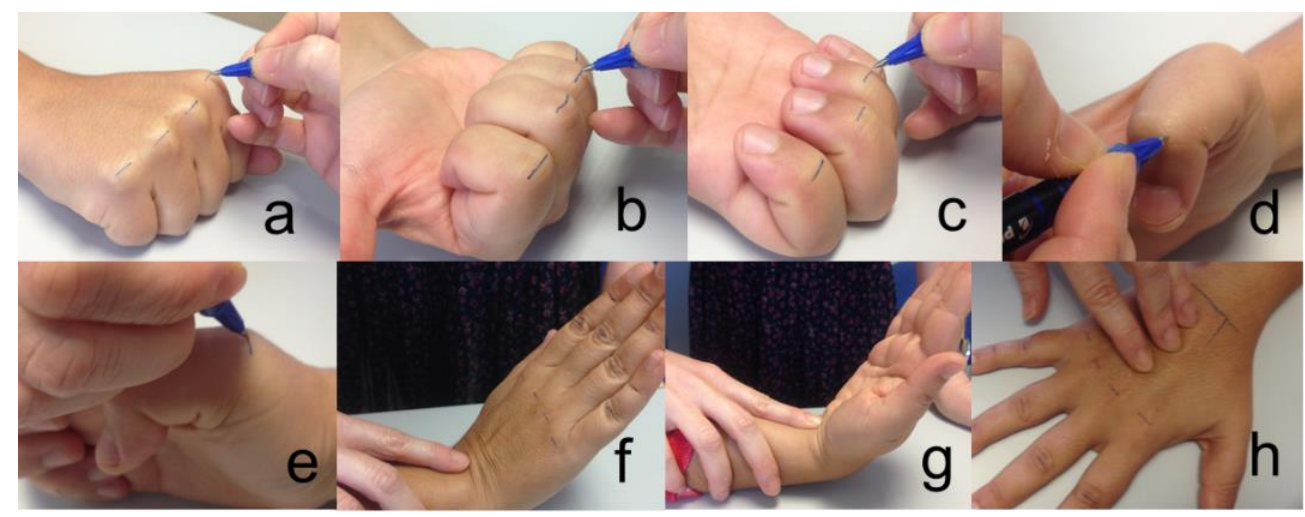

Figure 1. Marking limits of phalanges and metacarpals: from a) to e) limits of phalanges; f) and g) limits of hand (metacarpals with the wrist); h) limit of each metacarpal (direction). 


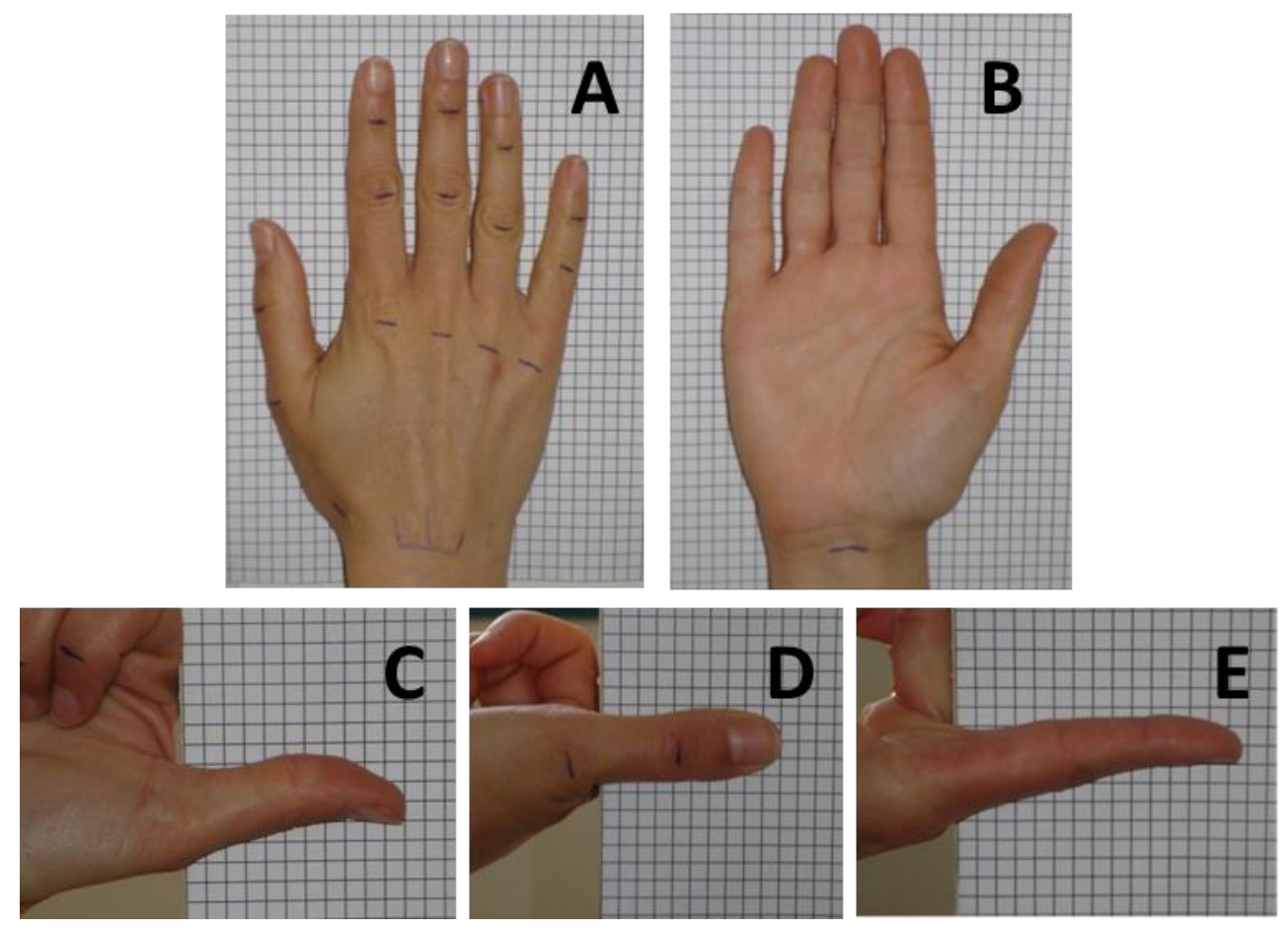

Figure 2. Example of the 5 photographs of the hand and fingers with landmarks for one subject. A: dorsal view of the whole hand, B: palmar view of the whole hand, C: lateral view of thumb, D: dorsal view of thumb, E: lateral view of index. 

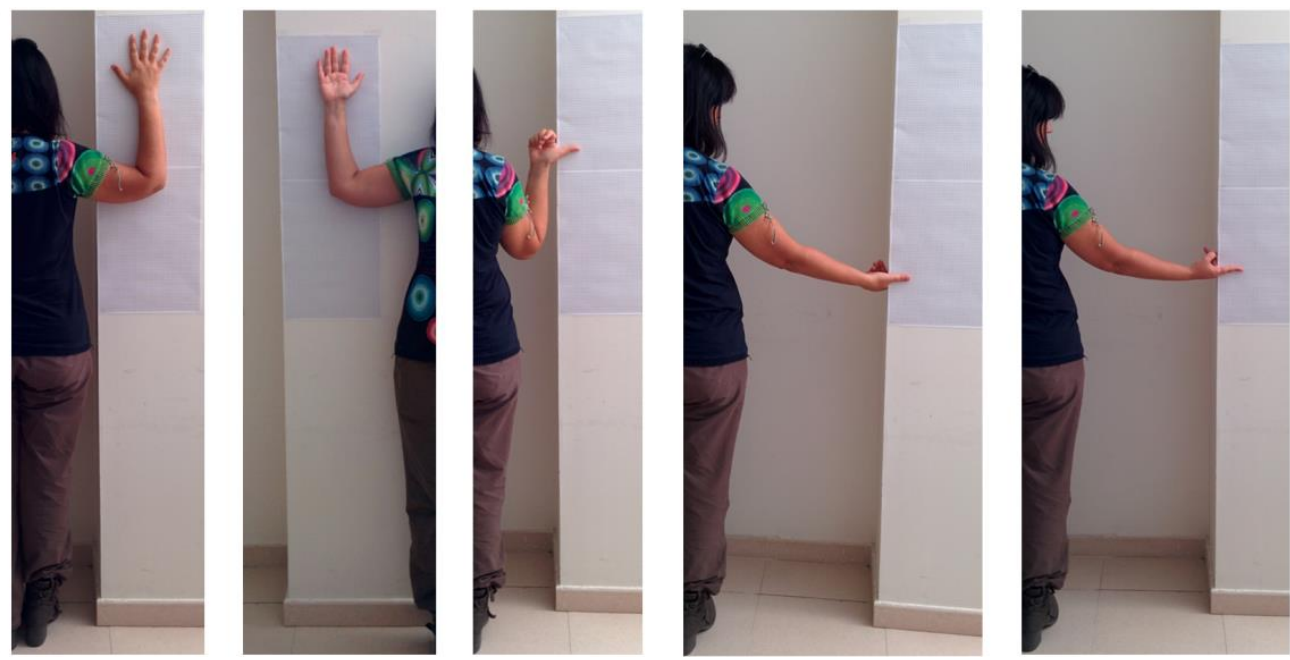

Figure 3. Example of the body and arm postures. From left to right: dorsal and palmar view of the whole hand, lateral and dorsal view of thumb, and lateral view of index. 


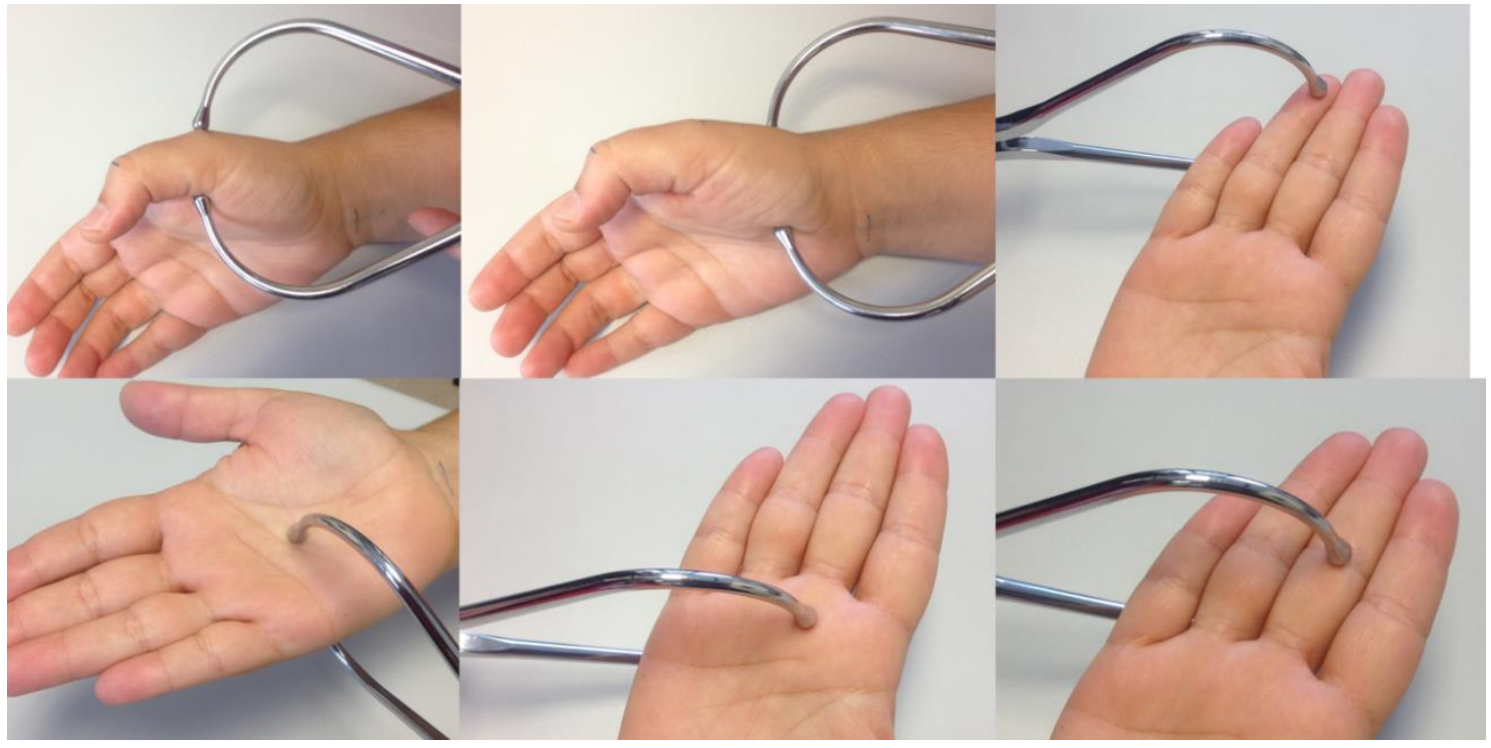

Figure 4. Examples of some hand depths measured with a spreading calliper. 

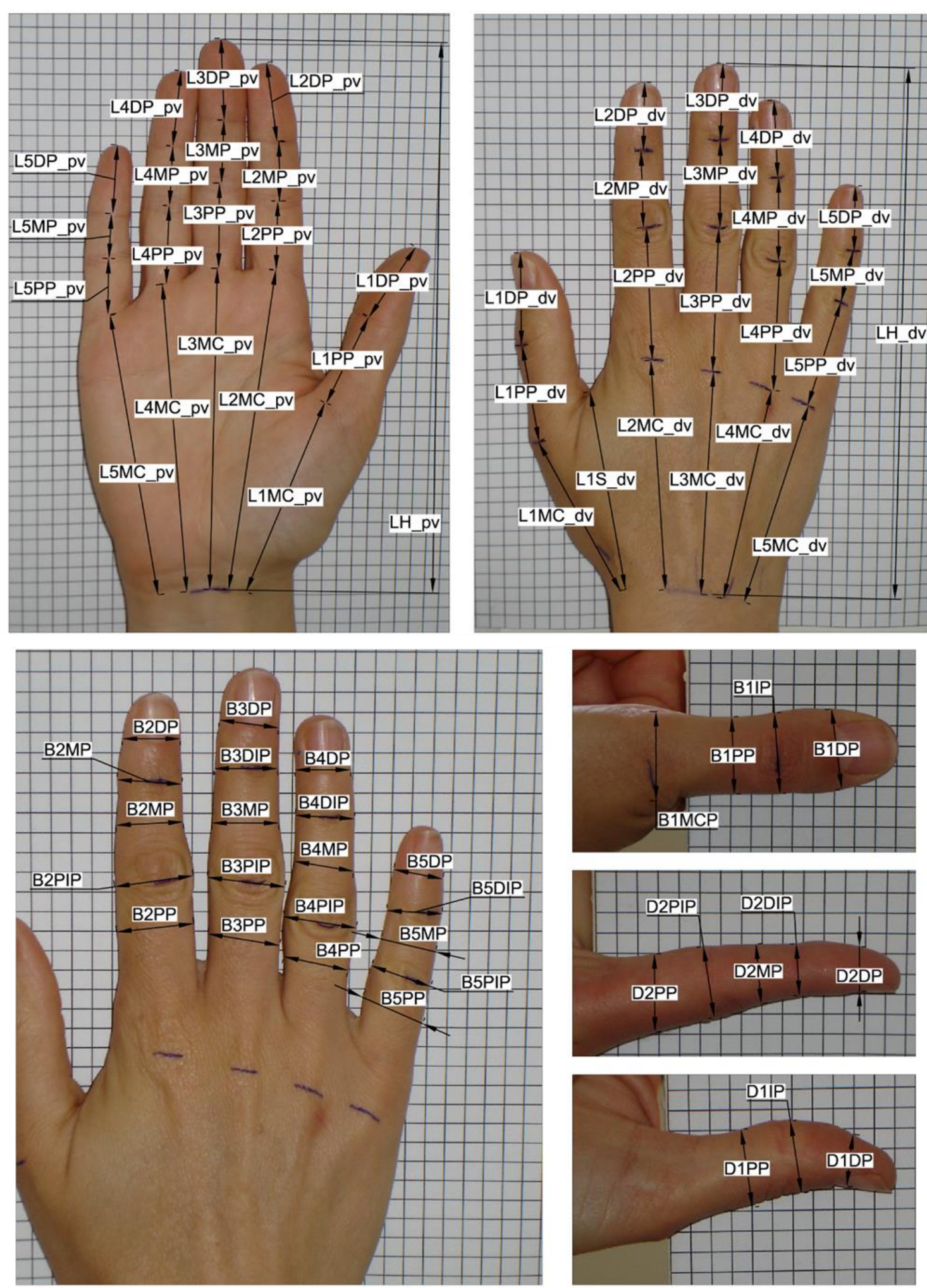

Figure 5. Hand measurements taken from photographs: all lengths and breadths, and 


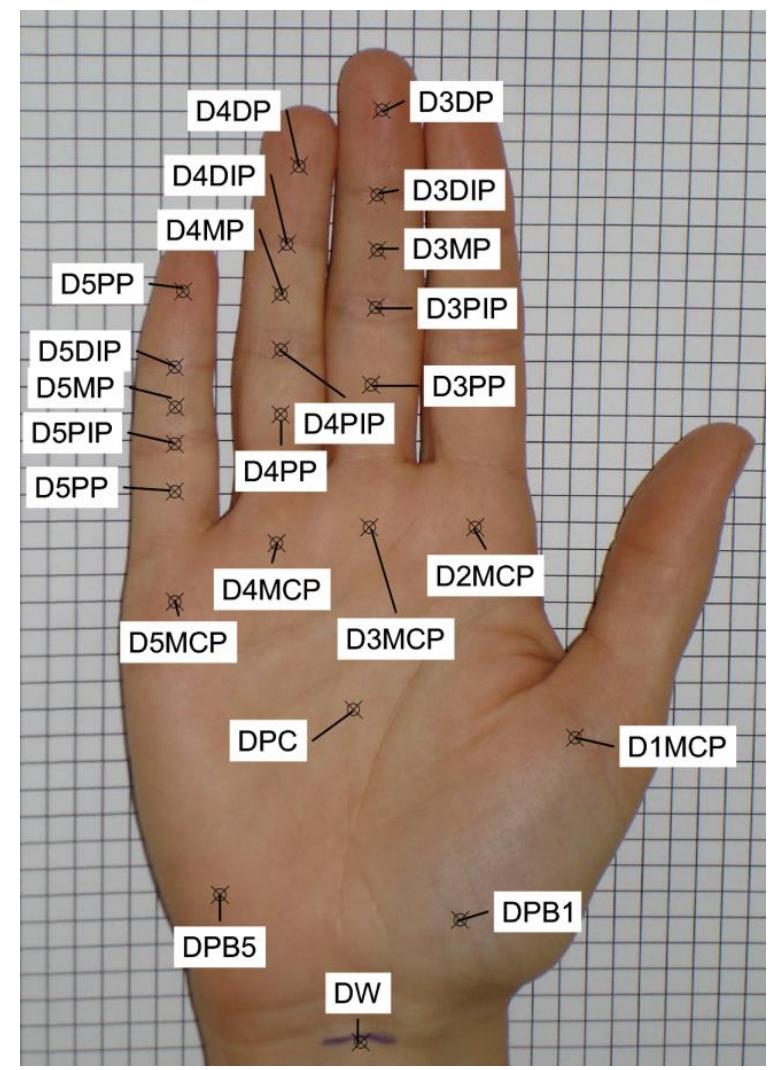

Figure 6. Points where the hand depths were measured manually. Note that depths related to the thumb (DPB1, D1MCP) were measured across the thumb (see Figure 4), not perpendicular to this image. 